
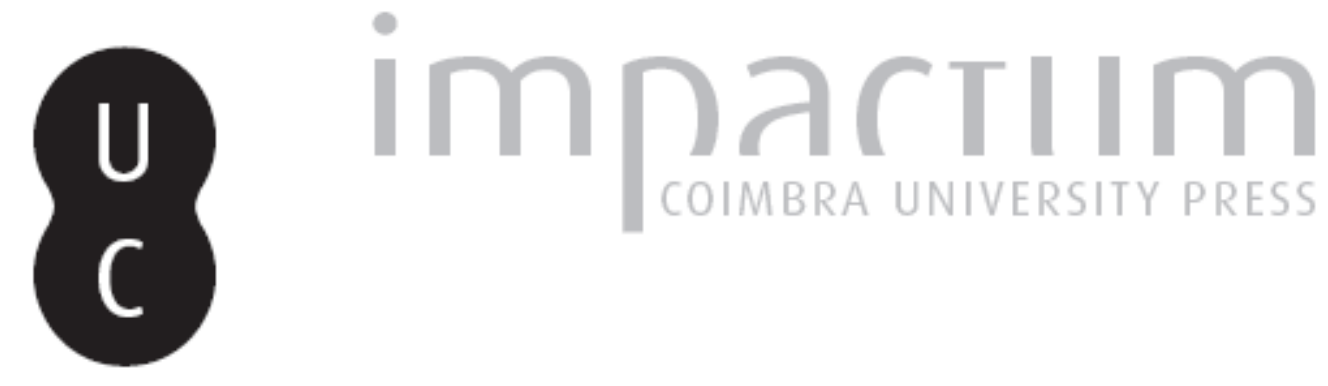

\title{
A estreita aliança entre os bispos e o Santo Ofício em Cabo Verde (1538-1646)
}

Autor(es): $\quad$ Santos, Matilde Mendonça dos

Publicado por: Centro de História da Sociedade e da Cultura

URL persistente:

URI:http://hdl.handle.net/10316.2/39430

DOI:

DOI:http://dx.doi.org/10.14195/1645-2259_12_9

Accessed : $\quad$ 26-Apr-2023 11:20:34

A navegação consulta e descarregamento dos títulos inseridos nas Bibliotecas Digitais UC Digitalis, UC Pombalina e UC Impactum, pressupõem a aceitação plena e sem reservas dos Termos e Condições de Uso destas Bibliotecas Digitais, disponíveis em https://digitalis.uc.pt/pt-pt/termos.

Conforme exposto nos referidos Termos e Condições de Uso, o descarregamento de títulos de acesso restrito requer uma licença válida de autorização devendo o utilizador aceder ao(s) documento(s) a partir de um endereço de IP da instituição detentora da supramencionada licença.

Ao utilizador é apenas permitido o descarregamento para uso pessoal, pelo que o emprego do(s) título(s) descarregado(s) para outro fim, designadamente comercial, carece de autorização do respetivo autor ou editor da obra.

Na medida em que todas as obras da UC Digitalis se encontram protegidas pelo Código do Direito de Autor e Direitos Conexos e demais legislação aplicável, toda a cópia, parcial ou total, deste documento, nos casos em que é legalmente admitida, deverá conter ou fazer-se acompanhar por este aviso.

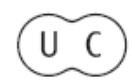


evista de História da Sociedade e da Cultura

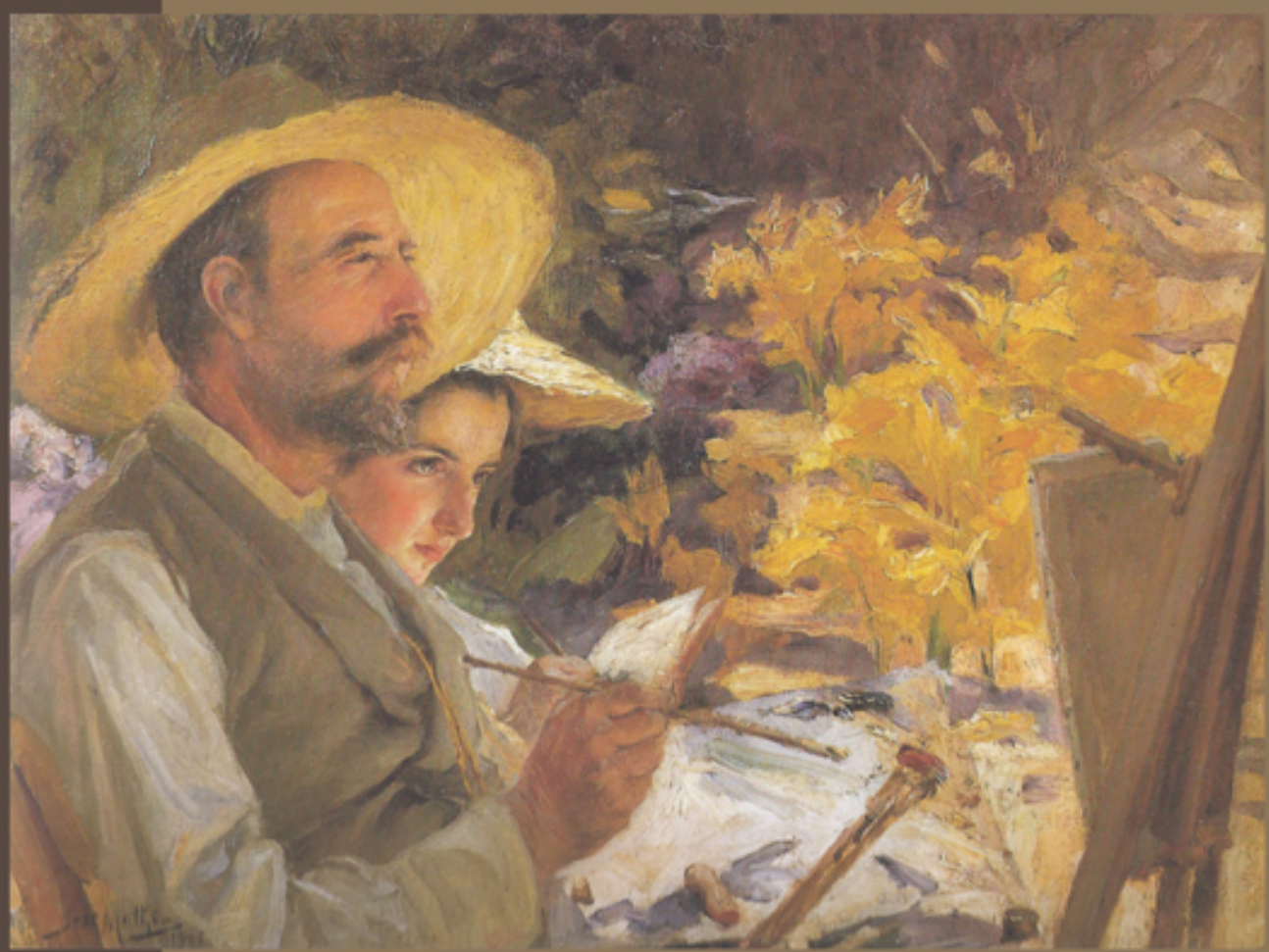

Centro de História da Sociedade e da Cultura Universidade de Coimbra 


\title{
A estreita aliança entre os bispos e o Santo Ofício em Cabo Verde (1538-1646)*
}

\author{
Matilde Mendonça dos Santos \\ Doutoranda em Altos Estudos em História: Época Moderna - Universidade de Coimbra \\ Centro de História de Além-Mar (CHAM) e \\ Centro de História da Sociedade e da Cultura (CHSC) \\ matildemsantos@yahoo.com.br \\ Texto recebido em /Text submitted on: 03/11/2011 \\ Texto aprovado em /Text approved on: 19/04/2012
}

Resumo/Abstract:

Neste artigo pretende-se analisar a relação que o Santo Ofício estabeleceu com os bispos da diocese de Cabo Verde, nos séculos XVI e XVII, atendendo à sua evolução ao longo deste período. Analisar-se-á, igualmente, a ligação do Santo Ofício com os outros organismos de poder, quer eclesiásticos quer seculares. Por fim, abordar-se-á ainda o impacto da acção inquisitorial no arquipélago.

This article aims to analyze the relationship that the Holy Office established with the bishops of the diocese of Cape Verde, and its evolution during the sixteenth and seventeenth centuries. Further, the connection between the Holy Office with other organizations of power, whether ecclesiastical or secular, will also be analyzed. Lastly, this study seeks to address the impact of the inquisitorial action in the archipelago.

Palavras chave/Keywords:

Bispos; Inquisidores; Inquisição; Cabo Verde.

Bishops; Inquisitors; Inquisition; Cape Verde.

* Neste artigo apresentam-se, resumidamente, as principais conclusões da dissertação de mestrado Os bispos e o Tribunal do Santo Ofício no arquipélago de Cabo Verde (1538-1646), defendida na Faculdade de Letras da Universidade de Coimbra, em Janeiro de 2011. 


\section{Introdução}

Embora, como afirma Giuseppe Marcocci, as relações entre os bispos e os inquisidores tenham ocupado um lugar central na historiografia recente, no que toca à justiça eclesiástica no mundo católico da Idade Moderna ${ }^{1}$, grande parte dos trabalhos sobre este tema têm como objecto de análise o território do Reino. Relativamente a Cabo Verde, a historiografia começa agora a dar os seus primeiros passos.

No presente estudo, abordaremos, resumidamente, a relação entre os bispos e o Santo Ofício em Cabo Verde, entre os séculos XVI e XVII, mais precisamente o período compreendido entre 1538 e 1646, numa perspectiva evolutiva, desde o primeiro bispo residente, D. João Parvi, até ao último da era filipina, D. Frei Lourenço Garro, o qual permaneceu no bispado até 1646. Outro aspecto a analisar é o impacto da acção inquisitorial na sociedade cabo-verdiana.

A partir de uma abordagem diacrónica propõe-se uma análise que se desenvolve em duas partes: primeiramente apresentar-se-ão os organismos de apoio à Inquisição, com destaque para a reconstituição da acção dos diferentes bispos. De seguida, incidir-se-á sobre o impacto da acção inquisitorial.

\section{Organismos de apoio à Inquisição: eclesiásticos e civis}

Para implantação e enraizamento da Inquisição em Cabo Verde foi decisivo o apoio recebido dos bispos, embora o auxílio de outras autoridades locais, quer eclesiásticas quer civis, também tenha sido relevante. Neste sentido, a cooperação do Santo Ofício com os organismos de poder local foi determinante: por um lado, o envolvimento das diversas autoridades locais desde o início, assumindo a responsabilidade da entrada do Santo

1 Ver MARCOCCI, Giuseppe-O arcebispo de Braga, D. Frei Bartolomeu dos Mártires (1559-82). Um caso de inquisição pastoral?. Revista de História da Sociedade e da Cultura. 9 (2009), p. 119-146. 
Ofício $^{2}$. Por outro lado, e digno de assinalar, a intervenção activa dos prelados, embora a sua presença nem sempre tenha sido regular.

Deste modo, importa sublinhar que a Inquisição estabelecida na década de 40 do século $\mathrm{XVI}^{3}$, beneficiou do forte auxílio das diferentes autoridades já instaladas, que muito ajudaram à sua implantação. A partir da acção dos diversos prelados visa-se perceber o apoio que concederam à implantação da Inquisição em Cabo Verde ${ }^{4}$.

\subsection{Os primeiros bispos em acção}

Esta incursão inicia-se com o bispo D. João Parvi. Este, na primeira acção que se lhe conhece, delegou as suas competências inquisitoriais no deão da Sé de Santiago, Francisco Homem. Neste âmbito deu-se o início e desenvolveu-se a actividade inquisitorial. O processo de Branca Dias que marca o início da actividade da Inquisição em Cabo Verde, data de $1543^{5}$, é esclarecedor quanto à cooperação entre as diferentes autoridades locais, uma vez que estiveram envolvidas várias instâncias de poder. Da prisão da ré, preparação do auto, até ao envio da mesma para o Tribunal da Inquisição

2 Temendo uma grande afluência dos cristãos-novos às ilhas, para fugir às malhas da Inquisição criada em Portugal, em 1536, as autoridades locais, escreveram cartas aos responsáveis do Reino solicitando também a implementação do Tribunal da Fé no arquipélago, cf. DGA/TT - Corpo Cronológico, parte 1, maço 75, nº 85; DGA/TT, Inquisição de Évora, Visitas, Livro 588, fls. 8-11.

3 Ao contrário do que habitualmente tem sido defendido a chegada da Inquisição a Cabo Verde aconteceu na década de 40 do século XVI, como se pode comprovar pela data da instauração do primeiro processo (1543). Esta entrada nas ilhas decorre da presença no território dos cristãos-novos. Entretanto, outros motivos também estiveram na sua base, nomeadamente de ordem económica e política, cf. DGA/TT, Inquisição de Lisboa, Processo $n^{0}$ 5729. Para mais informações sobre a entrada do Santo Ofício em Cabo Verde, ver SANTOS, Matilde Mendonça - Os bispos e o Tribunal do Santo Ofício no arquipélago de Cabo Verde (1538-1646). Coimbra: [s. n.], 2010 (dissertação de Mestrado em História Moderna apresentada à Faculdade de Letras da Universidade de Coimbra).

4 Metodologia com base no estudo de José Pedro Paiva, que propõe avaliar as relações entre a Inquisição e o episcopado a partir da reconstituição do desempenho de um conjunto de bispos, ver PAIVA, José Pedro - Os bispos e a Inquisição portuguesa (1536-1613). Lusitania Sacra. 2a série, 15 (2003), p. 48.

5 O processo de Branca Dias constitui o mais ancestral vestígio que actualmente se conhece da presença da Inquisição no arquipélago, cf. DGA/TT, Inquisição de Lisboa, Processo $n^{\circ} 5729$. 
de Lisboa, está bem visível a colaboração indispensável das distintas autoridades: o meirinho da serra, o deão e provisor episcopal Francisco Homem e o seu escrivão ${ }^{6}$.

Porém, isto não significa que tudo decorria em consonância com as regras estabelecidas pelo Tribunal da Fé. Constata-se que algumas medidas levadas a cabo por Francisco Homem no processo de Branca Dias, contrariavam o estipulado pelo Santo Ofício, nomeadamente o envio do auto acompanhado da presa - porque a Inquisição não prendia ninguém sem antes confirmar a actuação ilícita dos acusados ${ }^{7}$. Norma que nem sempre se observou em Cabo Verde, principalmente na fase inicial, quando os prelados ao invés de enviarem os autos aos inquisidores para analisarem, prendiam imediatamente os réus sem aguardarem pela competente decisão inquisitorial ${ }^{8}$. Na óptica de Filipa Ribeiro da Silva, muitos colaboradores "oficiosos" agiram por conta própria, sem nenhum tipo de indicação relativo aos procedimentos a adoptar'. Embora corroboremos a afirmação, atrever-nos-íamos a dizer que esta situação só se verificou porque a Inquisição não tinha ainda determinado uma linha de orientação bem organizada, por se encontrar no primeiro difícil decénio de actividade ${ }^{10}$, como é perceptível pelas datas em que foram elaborados os primeiros documentos que lhe serviram de guia ${ }^{11}$. O período

6 Ver DGA/TT, Inquisição de Lisboa, Processo n ${ }^{\circ}$ 5729, fls. 17-17v.

7 Ver PAIVA, José Pedro - Bruxaria e superstição num país sem "caça às bruxas" 1600-1774. Lisboa: Editorial Notícias, 2002, 2. ${ }^{\text {a }}$ edição, p. 199.

8 Assim sucedeu, por exemplo, com o processo de Branca Dias: "Remeto estes autos com esta presa ao senhor Jam de Melo ynquisydor comforme a provisão do senhor bispo para que proveja no caso como parecer justiça [...]”, cf. DGA/TT, Inquisição de Lisboa, Processo $\mathrm{n}^{\circ}$ 5729, fl. 22.

9 Ver SILVA, Filipa I. Ribeiro da - A Inquisição em Cabo Verde, Guiné e São Tomé e Príncipe (1536 a 1821): contributo para o estudo da política do Santo Ofício nos territórios africanos. Lisboa: [s. n.], 2002 (dissertação de mestrado apresentada à Faculdade de Ciências Sociais e Humanas da Universidade Nova de Lisboa), p. 74.

${ }^{10}$ Ver MARCOCCI, Giuseppe - La fede di un impero: L'Inquisizione nel mondo portoghese del Cinquecento, in Atti dei Convegni Lincei 260. A Dieci anni dall'apertura dell'Archivio della Congregazione per la Dottrina della Fede: Storia e archivi dell'Inquisizione. Roma: Academia Nazionale dei Lincei, 2011, p. 170.

${ }^{11}$ As primeiras linhas orientadoras elaboradas pelo cardeal D. Henrique com o seu Conselho, data de 1541. O primeiro Regimento de 1552 e os quatro que se seguiram (o de $1570,1613,1640$ e 1774) com alguns reajustes, foram todos de extrema importância quer como elemento de definição estatutária do Tribunal quer como conformadores da sua acção, ver BETHENCOURT Francisco - A Inquisição, in AZEVEDO, Carlos Moreira (dir.) História Religiosa de Portugal. Lisboa: Círculo de Leitores, 2000, vol. 2, p. 104. 
de organização e afirmação do Santo Ofício no arquipélago coincide com o tempo também de organização e afirmação desta instituição em Portugal, como considerou Joaquim Romero Magalhães - o período entre 1548 e 1572 - visto que nestes anos se assumiram medidas essenciais para esse processo $^{12}$. Neste sentido, consideramos que os colaboradores da Inquisição nas ilhas tinham dificuldades na sua actividade por falta de conhecimento das regras a seguir. Pela razão exposta actuavam por iniciativa própria com intuito de prestar bom serviço ao Tribunal da Fé.

Embora não esteja irrefutavelmente evidenciado, tudo indica que o Santo Ofício pôde contar com o apoio do bispo D. João Parvi.

Num âmbito diferente, vejamos a relação da Inquisição com outros agentes eclesiásticos, por altura da sede vacante (1546-1553). Para aqui, importa referenciar o caso da interferência do vigário-geral, Gaspar Silveira, nos assuntos da Inquisição, embora sem autorização para o efeito. A sua acção neste plano criou um clima de desconfiança do Santo Ofício, como se percebe pela provisão do cardeal D. Henrique, datada de 1551: “[... . mandamos ao dito Gaspar Sylveira Que mais nom emtenda nem se emtrometa nos negócios que tocarem a esta Imquisyção [... $]^{\prime \prime 13}$. Como bem demonstrou Giuseppe Marcocci, mesmo mantendo o complexo relacionamento entre o Santo Oficio e as autoridades diocesanas no mundo português, aqui tratava-se de um ponto no qual se deveria agir com firmeza: Gaspar Silveira foi intimado a desistir de toda a iniciativa, sob a severa ameaça de excomunhão, do pagamento de 500 cruzados e de ser punido ${ }^{14}$. Posteriormente, o cabido da Sé destituiu Gaspar Silveira do cargo que desempenhava. Possivelmente, na origem da destituição do vigário-geral está o facto de o cardeal D. Henrique o ter repreendido.

A par da desconfiança e do descontentamento perante a acção de Gaspar Silveira, foi notório também o apoio do cabido, como se pode constatar através da troca de correspondência com as autoridades do Reino: "[...] estamos ag[u]ardando [...] prellado, para o serviço de Deus e descar[r]ego

12 Ver MAGALHÃES, Joaquim Romero - Em busca dos tempos da Inquisição (1573-1615). Revista de Histórias das Ideias. 9 (1987), p. 193.

${ }^{13}$ Cf. DGA/TT, Inquisição de Lisboa, Cadernos do Promotor, Livro 840, fl. 8.

${ }^{14}$ Ver MARCOCCI, Giuseppe - La fede..., cit., p. 173. 
da consçiênçia de Vossa Alteza"15. Este documento demonstra claramente que as autoridades do Reino se mantinham informadas sobre o que se passava nas ilhas, mesmo no período de sede vacante.

O terceiro bispo de Cabo Verde, D. Frei Francisco da Cruz (1553-1571) ${ }^{16}$, cónego regrante de Santo Agostinho, esteve à frente da diocese, num período de grande desenvolvimento económico e num tempo em que muitos interesses dos altos dignitários convergiam possibilitando assim uma maior colaboração entre as diferentes esferas do poder, desde o eclesiástico ao civil e judicial ${ }^{17}$.

Desde o início da sua actividade D. Frei Francisco da Cruz desenvolveu acções relevantes, quer no que concerne à organização da diocese quer no papel que desempenhou como um importante colaborador da Inquisição. Este prelado reforçou significativamente a colaboração dos bispos com os inquisidores, iniciada no tempo de D. João Parvi, a qual se revelaria de extrema importância para o Santo Ofício, apesar de algumas dificuldades que surgiram, mas que foram resolvidas.

A cooperação entre o bispo e a Inquisição está bem patente no processo da família Dias. A 17 de Dezembro de 1558 na cidade de Santiago de Cabo Verde, D. Frei Francisco da Cruz, acompanhado pelo escrivão Jorge de Andrade, juiz ordinário Vicente Galvão, meirinho da correição António Dordio, meirinho eclesiástico António da Costa e pelo chantre Jerónimo Fernandes, foram a casa de Mécia Dias, mulher de Manuel Dias, que fora morador e feitor na Ilha do Fogo e à data estava em Portugal. Prenderam-na e a sua filha Inês Dias, por suspeitas de judaísmo. Mais tarde, a 22 de Fevereiro de 1559, o bispo mandou o escrivão e o meirinho António da Costa prender Branca Dias, outra filha de Mécia Dias. Em Julho do mesmo ano o prelado remeteu as três mulheres presas e Manuel Dias para o Santo Ofício

${ }^{15}$ Cf. BRÁSIO, Padre António - Monumenta Missionaria Africana. África Ocidental (1500-1569). Lisboa: Agência-Geral do Ultramar, 1963, vol. II, $2^{a}$ série, p. 444-445 (Carta do cabido de Cabo Verde a El-Rei D. João III, 4 de Julho de 1552).

${ }^{16}$ Francisco da Cruz foi o terceiro bispo nomeado para a diocese de Cabo Verde, mas o segundo a ir residir no bispado, a seguir ao bispo D. João Parvi.

${ }^{17}$ Ver SANTOS, Maria Emília Madeira e SOARES, Maria João - Igreja, Missionação e Sociedade, in SANTOS, Maria Emília Madeira (coord.) - História geral de Cabo Verde. Lisboa/Praia: Centro de Estudos de História e Cartografia Antiga, Instituto de Investigação Científica Tropical; Instituto Nacional da Cultura de Cabo Verde, 1995, vol. II, p. 385. 
de Lisboa, bem como os autos das culpas ${ }^{18}$. Inicialmente, à semelhança do seu antecessor, o bispo remetia o auto juntamente com os presos, sem o parecer do inquisidor, mas depois viria a consertar com ele.

No quadro da relação entre o prelado e a Inquisição, a realização das visitas pastorais foi sem dúvida um contributo relevante, uma vez que o uso deste mecanismo de controlo dos desvios comportamentais foi de extrema importância para o Santo Ofício nas ilhas, numa altura que não havia qualquer projecto de visitação inquisitorial para Cabo Verde ${ }^{19}$. Foi igualmente através das visitas episcopais, durante as quais se recolhiam denúncias (algumas viriam a constituir-se em processos inquisitoriais) que, posteriormente, eram reencaminhados para a Inquisição de Lisboa ${ }^{20}$ vários presos, como por exemplo sucedeu com a família Dias.

Situemo-nos agora no quadro da cooperação da Inquisição com outras instâncias de poder fixadas no arquipélago, entre as quais destacamos o corregedor e o governador. Uma colaboração diversificada entre o antístite e o corregedor foi um importante apoio à actuação do Santo Ofício, em Cabo Verde, especialmente na perseguição aos grupos de lançados (também denominados de tangomaos) ${ }^{21}$, estabelecidos na costa da Guiné, sendo cristãos-novos ou não ${ }^{22}$. Segundo Maria Emília Madeira Santos e Maria João Soares, o lançado não estava dentro do foro inquisitorial ${ }^{23}$.

${ }^{18}$ Ver DGA/TT, Inquisição de Lisboa, Processo n ${ }^{\circ} 13107$, fl. 11v.

${ }^{19} \mathrm{O}$ primeiro indício de visitação inquisitorial em Cabo Verde, data de 1581. Esta e outras propostas de visitas inquisitoriais que se lhe seguiram, nos finais do século XVI e segunda década do século XVII, não deixaram qualquer vestígio da sua realização. É de crer que a actividade inquisitorial em Cabo Verde tenha contado fundamentalmente com a colaboração das autoridades locais pré-existentes, mormente os bispos.

${ }^{20}$ Tribunal distrital com jurisdição sobre o arquipélago de Cabo Verde.

${ }^{21}$ Trata-se de um grupo de europeus (cristãos, judeus e cristãos-novos), de mestiços e de pretos forros que viviam e comerciavam sem autorização régia na costa africana, cf. CARREIRA, António - Cabo Verde: formação e extinção de uma sociedade escravocrata (1460-1878). Lisboa: Instituto Cabo-verdiano do Livro, 1983, $2^{\text {a }}$ edição, p. 53-78.

${ }^{22} \mathrm{Na}$ base da cooperação entre o bispo e o corregedor está uma mercê do rei ao bispo de Cabo Verde, onde manda que o braço secular faça cumprir as sentenças dos que são rebeldes ao foro do bispo e seus vigários. Denota-se uma ligação formal entre a jurisdição eclesiástica e a jurisdição civil, ver BRÁSIO, Padre António - Monumenta ..., vol. II, cit., p. 477-478 (Mercê ao Bispo de Cabo Verde de 30 de Maio de 1560); SANTOS, Maria Emília Madeira e SOARES, Maria João - Igreja..., cit., p. 386.

${ }^{23}$ As autoras contrariam a própria proposta apresentada, inicialmente, quando afirmam que o braço secular e episcopal estendem a sua acção às questões da ortodoxia da fé e de 
Em nosso entender, ainda que o alvo preferencial do Santo Ofício fossem os cristãos-novos, como já foi mencionado por muitos, este não deixou de combater outros desvios aos preceitos da ortodoxia católica.

Numa acção conjugada o corregedor estendia a sua actividade à costa da Guiné e o bispo fazia autos de inquirição de testemunhas para remeter ao Tribunal da Fé24. Essa cooperação permitiu a prisão de algumas pessoas acusadas de heresia e alargou a actividade da Inquisição que estava localizada, sobretudo em Cabo Verde. Na tentativa de ampliar, o mais possível, a acção inquisitorial na Guiné os inquisidores solicitaram a intervenção do governador e do bispo, como demonstra o trecho que se segue: “aos 26 dias de Novembro de 1558 se deu a António Goncalvez piloto do navio esperança huãs cartas para o bispo do Cabo Verde e para o governador da mesma ilha para prenderem certos christãos novos" ${ }^{25}$. A prisão do Mestre Diogo ocorreu na sequência deste pedido. Na sua exposição o bispo D. Frei Francisco da Cruz diz que ouvira dizer que no rio São Domingos, alguns cristãos-novos se tinham reunido na noite do Natal de 1562, com máscaras de papel e vestidos contrafeitos para ridicularizar o nascimento de Cristo. Com efeito, depois de todos reunidos, chamaram um cristão-novo, de nome Mestre Diogo, fazendo-o vestir trajes de mulher e dizer: "Maria já pariu. E muitos diziam em resposta, com risos, já pariu o salvador que nos há-de salvar, outros diziam macho ou fêmea, uns respondiam macho, onde pariu [...]". Muitas pessoas que assistiram o acto ficaram, naturalmente, escandalizadas ${ }^{26}$. O prelado expôs este facto aos inquisidores e ficou a aguardar o parecer daqueles para proceder no caso. Este processo demonstra que o bispo estava a tentar conformar o seu desempenho com os procedimentos inquisitoriais. Isto porque, apesar do bom entendimento entre o episcopado e a Inquisição, existiram arestas a limar - de modo a evitar falhas - relativamente aos procedimentos a adoptar. Os inquisidores

perseguição aos grupos de lançados estabelecidos na costa da Guiné, fossem ou não cristãos-novos, ver SANTOS, Maria Emília Madeira e SOARES, Maria João - Igreja..., cit., p. 386 e 486.

${ }^{24}$ Ver SANTOS, Maria Emília Madeira e SOARES, Maria João - Igreja..., cit., p. 386.

${ }^{25}$ Cf. DGA/TT, Inquisição de Lisboa, Cadernos do Promotor, Livro 840, fl. 41.

${ }^{26}$ Cf. DGA/TT, Inquisição de Lisboa, Processo $n^{0} 233$, fl. 4. 
chamavam a atenção sobre o modo de actuar, pelo que enviavam instruções precisas sobre a forma de resolver as falhas dos processos ${ }^{27}$.

Neste âmbito outro caso exemplificativo é o processo da família Dias, onde D. Frei Francisco da Cruz seguiu as orientações dos inquisidores para normalizar a sua tarefa e aperfeiçoar a sua actuação. Assim, e por sugestão dos inquisidores, o prelado voltou a ouvir algumas testemunhas do caso da família Dias para ratificar os seus depoimentos ${ }^{28}$.

Os processos de Mestre Diogo e da família Dias evidenciam melhorias na actividade do bispo D. Frei Francisco da Cruz, já munido do documento com orientação dos inquisidores. Aí são visíveis os sinais de que as arestas começavam a limar-se ${ }^{29}$. Embora anteriormente o prelado, por vezes, não tenha actuado em consonância com o Santo Ofício, nesta altura procurou concertar o seu trabalho de acordo com o estipulado "[...] dela senão fará senão o que me mandarem [... $]^{30}$.

À medida que avançamos para o século XVII, verificam-se claramente melhorias na actuação dos bispos. Este período coincidiu também com a época do próprio esplendor da Inquisição, como afirmou Joaquim Romero Magalhães - de 1573 em diante estamos no tempo da sua expansão plena ${ }^{31}$. Os progressos conseguidos pela Inquisição, também se faziam sentir em Cabo Verde. Contudo, importa referir que a tentativa de uniformização da acção do Santo Ofício, no arquipélago, decorreu, provavelmente, dos esforços quer dos inquisidores quer dos bispos, como se pode comprovar pela troca frequente de correspondência entre as duas instâncias.

${ }^{27}$ Ver DGA/TT, Inquisição de Lisboa, Processo no 13107, fl. 19v; DGA/TT, Inquisição de Lisboa, Cadernos do Promotor, Livro n ${ }^{\circ}$ 840, fl. 29.

${ }^{28}$ Ver DGA/TT, Inquisição de Lisboa, Processo $n^{0} 13107$, fl. 19; DGA/TT, Inquisição de Lisboa, Cadernos do Promotor, Livro $n^{\circ}$ 840, fl. 29.

${ }^{29}$ Ver DGA/TT, Inquisição de Lisboa, Processo no 233 , fl. 2v; DGA/TT, Inquisição de Lisboa, Processo n ${ }^{\circ} 13107$, fl. 19.

${ }^{30}$ Cf. DGA/TT, Inquisição de Lisboa, Processo no 233, fl. 2v.

${ }^{31}$ Ver MAGALHÃES, Joaquim Romero - Em busca..., cit., p. 194. 


\subsection{A acção dos bispos D. Bartolomeu Leitão e D. Frei Pedro Brandão}

O quarto bispo de Cabo Verde, D. Bartolomeu Leitão (1572-1587), doutorado em Teologia, foi nomeado em $1572^{32}$. Embora não se conheçam actos pastorais significativos do bispo à frente da diocese que permitam entender melhor a sua acção, importa realçar a sua relação com a Inquisição, uma vez que recaíram sobre ele pesadas queixas sobre a sua conduta ${ }^{33}$.

O prelado foi acusado de corrupção, negligência administrativa e imoralidade, pelo que o papa Gregório XIII solicitou ao arcebispo de Lisboa, D. Jorge de Almeida, do qual a diocese de Cabo Verde era sufragânea, para the instaurar um processo, em $1581^{34}$. Por um lado, o arcebispo, também enquanto inquisidor-geral, teria interesse em esclarecer este caso, pelo poder que tinha para controlar o bispo e, por outro lado, para saber se as acusações pertenciam ou não ao foro inquisitorial. O licenciado João Gonçalves Arecio, primeiro visitador inquisitorial, nomeado para Cabo Verde em 1581, entre outras coisas, ficou incumbido de inquirir das anomalias sobre o desempenho do bispo D. Bartolomeu Leitão, e eventuais desculpas do mesmo ${ }^{35}$. Esta verificação, se foi levada a cabo, não deve ter confirmado a suspeita, pois o antístite manteve-se no bispado até ao fim da vida.

Apesar das denúncias de negligência do antístite e do consequente mandado de averiguação sobre a sua actuação, não se conhece qualquer

${ }^{32}$ Maria Emília Madeira Santos, Maria João Soares e Nuno da Silva Gonçalves apontam a nomeação de D. Bartolomeu para 1576, mas contrariamente ao que aludem a eleição deste prelado foi em 1572, confirmada pela cédula consistorial, ver BRÁSIO, Padre António-Monumenta Missionaria Africana. África Ocidental (1570-1600). Lisboa: Agência Geral do Ultramar, 1964, vol. III, $2^{\text {a }}$ série, p. 26-27 (Cédula Consistorial de Bartolomeu Leitão); SANTOS, Maria Emília Madeira e SOARES, Maria João - Igreja..., cit., p. 390; GONÇALVES, Nuno da Silva - A Igreja e a Cultura, in SERRÃO, Joel e MARQUES, A. H. de Oliveira (dir.), MATOS, Artur Teodoro de (coord.) - Nova História da Expansão Portuguesa: A Colonização Atlântica. Lisboa: Editorial Estampa, 2005, vol. III - Tomo 2, p. 210.

${ }^{33}$ Ver SANTOS, Maria Emília Madeira e SOARES, Maria João-Igreja..., cit., p. 390-391.

${ }^{34}$ Ver BRÁSIO, Padre António - Monumenta ..., vol. III, 2a série, cit., p. $86-87$ (Breve de Gregório XIII ao arcebispo de Lisboa de 16 de Fevereiro de 1581); GONÇALVES, Nuno da Silva - A Igreja..., cit., p. 207; SANTOS, Maria Emília Madeira e SOARES, Maria João - Igreja..., cit., p. 391.

${ }^{35}$ Ver DGA/TT, Conselho Geral do Santo Ofício, Livro 442, fl. 127. 
oposição do bispo à actividade do Santo Ofício, nem do Tribunal em relação a ele.

Atentemos num outro domínio - o da cooperação de outros agentes da administração episcopal na acção inquisitorial. Nesse restrito grupo destaca-se o papel desempenhado pelo cabido, principalmente por altura de sede vacante. Como habitual, na ausência do bispo, o cabido assumia o governo da diocese ${ }^{36}$. Situação que permitiu à Inquisição continuar a sua intervenção, mesmo na ausência do prelado na diocese, como é visível pelo processo desencadeado em 1587 pelo cabido contra André Rodrigues de Luna, homem pardo, cristão-velho, acusado de proposições heréticas ${ }^{37}$. Segundo a acusação o réu disse que não sabia porque razão é que Deus fez um homem rico e discreto, isto a propósito do comentário que algumas pessoas fizeram ao elogiarem um homem cristão-novo de ser discreto, apesar da sua riqueza. $\mathrm{Na}$ presença dos inquisidores, o réu admitiu a culpa, defendeu-se dizendo que só o fez para contrariar aquelas pessoas, por causa do encarecimento que faziam ao referido homem. Mas nunca teve dúvidas que Deus nosso senhor é "todo-poderoso" 38 .

O resultado da sentença de André Rodrigues, proferida no auto-da-fé realizado na sede da Inquisição de Lisboa, em Março de 1588, deveria ser lido publicamente na Sé da Ilha de Santiago, durante a missa de Domingo. $\mathrm{O}$ arguido deveria estar presente e manter-se de pé com a cabeça descoberta durante a leitura da referida sentença. A divulgação deste resultado tinha como finalidade mostrar que se castigavam todos que desafiavam os preceitos da Igreja e salientar que o escândalo que o arguido havia cometido publicamente não ficara sem castigo ${ }^{39}$. Este processo assume relevância, porque a actuação do cabido não implicou mudanças profundas no procedimento que anteriormente os bispos e seus agentes desencadeavam a favor do Tribunal da Fé.

\footnotetext{
${ }^{36}$ Ver SANTOS, Maria Emília Madeira e SOARES, Maria João - Igreja..., cit., p. 392.

${ }^{37}$ Ver DGA/TT, Inquisição de Lisboa, Processo n ${ }^{\circ}$ 12902, fl. 80.

${ }^{38}$ Ver idem, fls. $80-82 \mathrm{v}$.

${ }^{39}$ Ver idem, fls. $79-82 \mathrm{v}$.
} 
O quinto bispo nomeado para Cabo Verde, D. Frei Pedro Brandão $(1588-1606)^{40}$, carmelita, nomeado em 1588, residiu no bispado, mas por pouco tempo. No início da sua actuação foi visível a cooperação com o Santo Ofício, embora mais tarde tenham recaído sobre ele algumas acusações as quais não desencadearam nenhum tipo de contenda com esta instituição.

De acordo com alguns investigadores, quando foi para as ilhas, levou uma carta requisitória dos inquisidores de Lisboa, para proceder à prisão de dois irmãos suspeitos de judaísmo ${ }^{41}$. Quando da chegada a Cabo Verde, fora informado que os referidos irmãos estavam lançados na costa africana. Deste modo, incumbiu o seu visitador na Guiné da tarefa de os prender, mas avisou o Tribunal que esta seria uma tarefa difícil de concretizar, porque muitos cristãos-novos que se refugiavam na costa africana conseguiam escapar às investidas dos bispos, apesar do envio periódico de visitadores ${ }^{42}$.

O problema da costa da Guiné ${ }^{43}$ também já tinha incomodado D. Francisco da Cruz. Pelo que foi possível apurar e atendendo ao facto de que a questão da Guiné continuava a preocupar a Inquisição, o bispo D. Frei Pedro Brandão deu continuidade à acção de D. Francisco da Cruz referente aos lançados ${ }^{44}$. Para colmatar este problema o prelado contou com o auxílio do corregedor Amador Gomes Raposo, que tinha indicações do rei para devassar "[...] pessoas que andão nos Ryos ou en outras partes feitos tangomãos [...]" ${ }^{45}$. Tendo em atenção a presença significativa dos cristãos-novos na Guiné, resultado de uma cobertura inquisitorial deficiente, havia um problema objectivo a que era necessário pôr termo ${ }^{46}$. Apesar das dificuldades, as autoridades eclesiásticas e civis procuraram

${ }^{40}$ Ver PAIVA, José Pedro - Os bispos de Portugal e do Império (1495-1777). Coimbra: Imprensa da Universidade, 2006, p. 589.

${ }^{41}$ Ver SANTOS, Maria Emília Madeira e SOARES, Maria João - Igreja..., cit., p. 393.

${ }^{42}$ Ver ibidem.

${ }^{43}$ Espaço onde convergiam mercadores africanos e europeus de diferentes origens e a presença das autoridades coloniais era bastante débil, permitindo assim aos mercadores cristãos-novos e protestantes desfrutarem de livre movimentação e permanência na área, ver SANTOS, Maria Emília Madeira e SOARES, Maria João - Igreja..., cit., p. 487.

${ }^{44}$ Ver SANTOS, Maria Emília Madeira e SOARES, Maria João - Igreja..., cit., p. 393.

${ }^{45}$ Cf. BRÁSIO, Padre António - Monumenta..., vol. III, $2^{\mathrm{a}}$ série, cit., p. 158-164 (Regimento de alçada e poder a Amador Gomes Raposo de 17 de Março de 1588).

${ }^{46}$ Ver SANTOS, Maria Emília Madeira e SOARES, Maria João-Igreja..., cit., p. 486-487. 
resolver esta questão, denunciando a situação aos inquisidores e estes, por sua vez, enviaram ordens para perseguir e prender os culpados de heresia e encaminhá-los para o Reino.

Parece evidente no trecho que se segue, que o bispo procurava agir de acordo com as normas da Inquisição, de modo a evitar erros: "Peço a Vossas Mercês de me avisar o que nisto devo fazer, porque não queria errar em cousas de tanta importancia"47. A actuação do bispo neste plano, comprova que havia uma certa cultura de procedimento que se ia instalando e, à medida que o tempo passava e a experiência aumentava, a tendência foi para a diminuição da margem de erros cometidos pelos bispos quando desencadeavam um processo. Por conseguinte, não seguimos a proposta de que os bispos temiam cooperar com o Tribunal da Fé, por medo de “errar"48. Entendemos que o medo de "errar" estava relacionado mais com a preocupação e zelo na prestação de um bom serviço à Inquisição do que propriamente com o temor de colaborar com a instituição. Pelo que já foi dito, parece mais do que razoável dizer que os bispos de uma forma geral colaboraram activamente com o Santo Ofício, contribuindo assim para o seu enraizamento e fortalecimento, independentemente de terem ou não cometido erros durante o seu exercício.

Num plano diferente das relações com a Inquisição, surgiram controvérsias relativas ao bispo D. Frei Pedro Brandão sobre o seu envolvimento em actividades comerciais ilícitas ${ }^{49}$. Estas e outras acções desencadearam conflitos e desentendimentos entre o antístite, os moradores da cidade de Santiago e o capitão Brás Soares, os quais resultaram num conjunto de queixas mútuas, obrigando a constantes consultas da Mesa da Consciência e Ordens.

${ }^{47}$ Cf. BRÁSIO, Padre António - Monumenta ..., vol. III, 2 ${ }^{\mathrm{a}}$ série, cit., p. 204-206 (Carta de Frei Pedro Brandão a El-Rei de 11 de Julho de 1592).

${ }^{48}$ Ver SANTOS, Maria Emília Madeira e SOARES, Maria João - Igreja..., cit., p. 487.

${ }^{49}$ De acordo com o direito canónico e as Ordenações do Reino, a actividade comercial, estava interditada aos clérigos, especialmente ao bispo, que como representante máximo da diocese deveria servir de exemplo de boa conduta, para os seus subalternos, ver BRÁSIO, Padre António - Monumenta ..., vol. III, 2a série, cit., p. 379-380 (Carta Régia aos Governadores de Portugal de 3 de Abril de 1595); SANTOS, Maria Emília Madeira e SOARES, Maria João - Igreja..., cit., p. 394-395; GONÇALVES, Nuno da Silva Os Jesuitas e a Missão de Cabo Verde (1604-1642). Lisboa: Brotéria, 1996, p. 70. 
Perante esta situação, o bispo retirou-se da diocese e regressou ao Reino. Mesmo radicado em Lisboa, o prelado continua a participar nas actividades comerciais, como afirma o colector apostólico Decio Caraffa: “[...] e quanto a diligencia que o colector tem começado a fazer dos tratos e mercancias ilícitas do dito bispo, assy do tempo que residio como do que há que está nesta cidade, convém que proceda nella e que tire mais testemunhas, que não deve faltar, por ser cousa notoria e sabida de muitos" ${ }^{50}$. Contudo, apesar do protesto contra o exercício do bispo D. Frei Pedro Brandão, não existem referências a nenhuma acção concreta acerca da resolução do caso. Por outro lado, relativamente à sua relação com a Inquisição, também não há registos de nenhum mal estar. Todavia, em geral, a Inquisição confiava nos bispos, apesar de por vezes haver queixas de terem sido negligentes ${ }^{51}$.

Em suma, os comportamentos dos distintos agentes mostram a continuidade em relação à boa cooperação entre o poder inquisitorial e o poder episcopal e, ao mesmo tempo, a adaptação e a permanente actualização dos procedimentos, apesar de terem surgido queixas sobre o desempenho dos prelados acima referidos.

\subsection{Sinais de progressos num cenário inalterado: D. Frei Sebastião de Ascensão e D. Manuel Afonso Guerra}

Para fazer face à questão dos cristãos-novos na Guiné, que continuava por resolver ainda no século XVII, apesar dos sinais dos progressos alcançados relativamente ao procedimento dos bispos, as diferentes autoridades civis, eclesiásticas locais e do Reino, esforçaram-se na busca de mais parcerias a fim de resolverem o problema. Do Reino procurava-se continuar a munir os bispos nomeados para Cabo Verde de meios essenciais para a sua actuação. A partir do arquipélago procurava-se reforçar a actividade que vinha sendo

${ }^{50}$ Cf. BRÁSIO, Padre António - Monumenta Missionaria Africana. África Ocidental (1600-1622). Lisboa: Agência Geral do Ultramar, 1968, vol. IV, $2^{a}$ série, p. 29 (Carta Régia ao bispo Vice-Rei, Valhadolid de 26(?) de Dezembro de 1603); cito a partir de GONÇALVES, Nuno da Silva - Os Jesuitas..., cit., p. 71.

${ }^{51}$ Ver PAIVA, José Pedro - Bispos, Imprensa, Livro e Censura no Portugal de Quinhentos. Revista de História das Ideias. 28 (2007), p. 737. 
desenvolvida pelos distintos bispos desde o tempo de D. João Parvi. O novo prelado, D. Frei Sebastião de Ascensão (1611-1614), frade dominicano, segundo advertências do monarca, deveria levar uma comissão do inquisidor-geral, se aquele assim entendesse, para se inteirar da situação da Guiné.

O monarca incumbiu os governadores de Portugal de contactarem o inquisidor-geral, para tomarem medidas concretas sobre as diligências que o prelado deveria fazer na Guiné.

Ao governador de Cabo Verde foi confiada a prestação de ajuda ao bispo, a fim de levar a cabo a referida tarefa. Importa assinalar, o envolvimento activo do monarca na acção inquisitorial desenvolvida no ultramar, sobretudo na primeira metade do século XVII, altura em que se apresentaram algumas medidas estratégicas que deveriam ser implementadas, para solucionarem o problema da presença dos cristãos-novos em diferentes espaços ultramarinos. Neste âmbito, parece ter sido política da coroa envidar esforços no sentido de fazer evoluir a acção inquisitorial no império. Uma das apostas para a resolução da questão dos cristãos-novos no ultramar foi, sem dúvida, o reforço do poder episcopal em articulação com o poder inquisitorial. Resultando daí a dotação dos bispos com meios para intervenções mais eficazes. Também o fizera para o Brasil, ali sugerindo até a criação de um tribunal que fosse dirigido pelo bispo ${ }^{52}$. De modo geral, apesar dos parcos sinais de envolvimento do bispo D. Frei Sebastião de Ascensão na acção inquisitorial, a sua contribuição foi relevante na cooperação com o Tribunal, visto que há indicações de que o vigário, sediado em Cacheu, foi um dos denunciadores das irregularidades fiscais e financeiras do contratador João Soeiro ${ }^{53}$ e, provavelmente, de alguma irregularidade religiosa, tendo contado, possivelmente, com o auxílio do prelado, embora isso não esteja claramente evidenciado.

Em 1616, Cabo Verde, passou a dispor de um novo bispo, D. Manuel Afonso Guerra (1616-1624), embora tenha ido para a diocese somente na década de $20^{54}$.

${ }^{52}$ Ver PEREIRA, Ana Margarida Santos - A Inquisição no Brasil: aspectos da sua actuação nas capitanias do sul (de meados do século XVI ao início do século XVIII). Coimbra: Colecção Estudos (61), 2006, p. 68-70.

${ }^{53}$ Ver SANTOS, Maria Emília Madeira e SOARES, Maria João - Igreja..., cit., p. 402.

${ }^{54}$ Ver idem, p. 406. 
O bispo enfrentou, igualmente, os mesmos problemas que os seus predecessores em relação à costa africana, devido à forte presença dos cristãos-novos que continuaram no local, e a cuja permanência os visitadores episcopais não conseguiam obstar. Para resolver este problema de longa data, procurou-se mudar de estratégia através da nomeação de um comissário do Santo Ofício especialmente para a Guiné, de modo a garantir a presença efectiva dos agentes do Tribunal naquele local. Não se conhece, contudo, nenhum indício sobre a actuação de agentes inquisitoriais na região, pelo que é de admitir que esta ideia nunca se tenha consumado, ou, pelo menos, que tenha tido pouco impacto. Acresce que, numa altura em que já se tinham avançado algumas propostas de visitação inquisitorial e até nomeado vários comissários para a diocese de Cabo Verde, ainda que sem nenhuma notícia que as confirmem, foram as visitas pastorais que continuaram a ser um mecanismo fundamental de vigilância da população.

Com a questão da costa da Guiné por resolver, o bispo D. Manuel Afonso Guerra desencadeou uma série de acções concentradas no arquipélago, sobretudo através das visitas pastorais. Revelam-no exemplarmente a visita à Ilha do Fogo, realizada pelo arcediago da Sé de Santiago, a mando do prelado. Foi durante esta visita que o vigário Filipe Tavares foi acusado de afirmar em público que sabia mais do que aquilo que a Santa Madre Igreja ensinava. A acusação viria a ser provada através do interrogatório de testemunhas, levada a cabo pelo bispo.

Este caso é um bom exemplo do empenho de D. Manuel Afonso Guerra na causa da Inquisição e evidencia os avanços alcançados no que toca ao procedimento a seguir, particularmente quando afirma que fez as perguntas que lhe pareceram necessárias de acordo com o estipulado pelo Santo Ofício ${ }^{55}$.

Um outro aspecto importante a ter em conta é o facto de D. Frei Manuel Afonso Guerra ter sido provido governador interino de Cabo Verde pelo rei, em finais de 1622, após a morte do governador D. Francisco Rolim, tendo terminado o exercício do cargo em Março de 1624, quando da sua morte ${ }^{56}$. Este caso demonstra que a coroa se serviu recorrentemente dos

\footnotetext{
${ }^{55}$ Ver DGA/TT, Inquisição de Lisboa, Cadernos do Promotor, Livro 208, fls. 500-504v.

${ }^{56}$ Ver SANTOS, Maria Emília Madeira e SOARES, Maria João-Igreja..., cit., p. 407-408.
} 
bispos ao mais elevado nível da política de governação, tanto no Reino como no império ${ }^{57}$.

\subsection{Fortalecimento da hegemonia inquisitorial: o bispo D. Frei Lourenço Garro}

D. Frei Lourenço Garro (1625-1646), nomeado para o arquipélago em 1625, pertencia à Ordem de Cristo e tinha sido professor de Teologia na Universidade de Coimbra ${ }^{58}$. A sua actuação permite verificar alguns sinais de fortalecimento da hegemonia inquisitorial, em Cabo Verde. Contudo, em relação à costa da Guiné a questão da presença massiva dos cristãos-novos, continuava ainda por resolver, apesar do interesse do bispo na cobertura religiosa daquele território, embora por vezes bastante deficiente como se percebe pelas suas palavras: "não tenho mandado fazer diligência em Cacheu sobre os judeus da costa, porque o vigário que ora está nesta Ilha de Santiago, em Julho de 1635, há-de partir em Outubro"59.

Todavia, importa referir que enquanto a costa da Guiné continuava a apresentar algumas fragilidades, a actividade do antístite nas ilhas mostrava sinais de melhorias e de fortalecimento da hegemonia do Santo Ofício.

A excelente cooperação do bispo D. Frei Lourenço Garro reforçou a acção da Inquisição no arquipélago, dando continuidade a um projecto de boa colaboração entre os distintos bispos com os inquisidores. Desde a criação da Inquisição, como bem demonstrou José Pedro relativamente ao Reino, verificou-se um forte envolvimento e cooperação de vários bispos ${ }^{60}$. O auxílio deste prelado à Inquisição vislumbra-se nos processos de Cristóvão Cabral, acusado de sodomia e de Bento Rodrigues ou Bento de Jesus, preto forro, acusado de fingimentos de visões e revelações ${ }^{61}$. O primeiro

${ }^{57}$ Ver PAIVA, José Pedro - Os bispos de Portugal..., cit., p. 566.

${ }^{58}$ Ver SANTOS, Maria Emília Madeira e SOARES, Maria João - Igreja..., cit., p. 408; GONÇALVES, Nuno da Silva - A Igreja..., cit., p. 208.

${ }^{59}$ Cf. DGA/TT, Inquisição de Lisboa, Cadernos do Promotor, Livro 217, fl. 475.

${ }^{60}$ Ver PAIVA, José Pedro - Baluartes da fé e da disciplina. O enlace entre a Inquisição e os bispos em Portugal (1536-1750). Coimbra: Imprensa da Universidade, 2011, p. 156.

${ }^{61}$ Ver DGA/TT, Inquisição de Lisboa, Processo no ${ }^{\circ} 2248$; DGA/TT, Inquisição de Lisboa, Processo $\mathrm{n}^{\circ} 4806$. 
caso, de Cristóvão Cabral, é exemplar e mostra o cuidado que o bispo teve na preparação do auto. Ele informou a Inquisição sobre o sucedido em Cabo Verde através de uma carta para o inquisidor-geral, datada de 30 de Junho de 1633, na qual dizia que Gaspar Teles, criado de Cristóvão Cabral, governador de Cabo Verde, residente na Ilha de Santiago, fora algumas vezes procurá-lo queixando-se do seu senhor, solicitando apoio para o livrar dele, porque várias vezes o obrigara a cometer o "pecado nefando, concorrendo activamente", enquanto ele, confitente, ficava "paciente". Sempre que não consentia no acto, era espancado, tendo, inclusive, recebido por vezes muitas bofetadas. Por isso recorreu ao bispo, pediu-lhe protecção e ajuda para sair do arquipélago, de modo a "livrar-se da ocasião". O prelado rapidamente providenciou a sua partida para Lisboa, bem como o envio de todos os papéis que tratassem desta matéria ${ }^{62}$.

Os inquisidores, após receberem a missiva do bispo de Cabo Verde com um auto e uma certidão com o testemunho de Gaspar Teles, e recordando que se tratava de um réu reincidente cuja culpa a Mesa já havia confirmado, emitiram um mandado de prisão e sequestro dos bens de Cristóvão Cabral ${ }^{63}$. $\mathrm{O}$ facto de o processo não estar concluído não permite que se conheça o desenrolar deste caso.

No que diz respeito ao segundo caso, de Bento Rodrigues, o bispo preparou o auto e remeteu-o à Inquisição de Lisboa que, depois de o analisar, emitiu o mandado de prisão. Segundo as palavras do bispo, Bento Rodrigues andava pela ilha de Santiago com traje de "ermitão", designando-se frade professo da terceira Ordem de São Francisco, despertando o interesse de muitas pessoas a seguirem a sua seita. Ele faria ainda pregações, ensinava a doutrina, persuadindo alguns a deixar ir seus escravos e tentava convencer pessoas casadas a apartarem-se e não fazerem "vida marital", o que provocara grande escândalo. A tentativa do prelado de impedir o intento e extinguir a irmandade não foi viável, por causa do bom exemplo que davam publicamente. Entretanto, numa reunião em São Miguel, o réu disse ter tido uma revelação em que lhe apareceu Nossa Senhora. O bispo chamou-o e advertiu-o que a referida revelação, presumivelmente, era alguma ilusão

\footnotetext{
${ }^{62}$ Ver DGA/TT, Inquisição de Lisboa, Processo no 12248, fls. 6-9.

${ }^{63}$ Ver idem, fl. 11.
} 
do demónio, mas ele defendeu que se tratava de uma visão verdadeira. A propósito, D. Frei Lourenço Garro solicitou-lhe uma declaração da referida revelação por escrito, ao que ele acedeu. $\mathrm{O}$ bispo remeteu o documento ao Santo Ofício ${ }^{64}$.

A actividade do bispo D. Frei Lourenço Garro, dá-nos uma imagem do fortalecimento da hegemonia do Santo Ofício no arquipélago, de acordo com o procedimento já previsto nas cartas de comissão, como por exemplo se verificou nos casos de Cristóvão Cabral e Bento Rodrigues, em que se enviaram os autos para os inquisidores se pronunciarem ${ }^{65}$.

\section{Impacto da acção inquisitorial}

No geral, como já salientou José Pedro Paiva, a entrada da Inquisição nas localidades deixava sinais profundos e duradouros, quer em relação à vida individual de cada um, quer sobre a comunidade globalmente considerada. A partir das primeiras prisões até à saída em auto-da-fé dos processados, vivia-se em clima de medo e intranquilidade, não só pelas relações familiares com os presos, mas também pelas ameaças feitas tanto por cristãos-velhos como por cristãos-novos. Na comunidade cristã-nova, todos se temiam reciprocamente, especialmente aqueles com quem se mantinha algum tipo de atrito $^{66}$.

Atendendo ao facto de que a entrada da Inquisição em Cabo Verde ocorreu na sequência de uma conjuntura de múltiplas contestações à presença dos cristãos-novos, a perseguição foi dirigida, sobretudo, contra esse grupo particular, que se constituiu no principal alvo de suas campanhas. Tendo em atenção que a integração dos cristãos-novos na comunidade cristã-velha não foi completa, em Cabo Verde, sobretudo pela desconfiança face à gente de nação, todas as manifestações públicas estiveram sob o olhar atento da maioria

${ }^{64}$ Ver DGA/TT, Inquisição de Lisboa, Processo nº4806, fls. 5-5v.

${ }^{65}$ Ver DGA/TT, Inquisição de Lisboa, Processo $n^{\circ}$ 12248, fls. 6-9; DGA/TT, Inquisição de Lisboa, Processo nº4806, fl. 5 v.

${ }^{66}$ Ver PAIVA, José Pedro Paiva - As entradas da Inquisição, na Vila de Melo, no século XVII: pânico, integração/segregação, crenças e desagregação social. Revista de História das Ideias. 25 (2004), p. 199-200. 
da população, mas sobretudo dos cristãos-velhos. Segundo Federico Palomo, do ponto de vista inquisitorial, a conservação de alguns costumes ligados às formas de vida e de religiosidade judaica, possibilitavam a identificação de eventuais culpados. Deste modo, após a criação da Inquisição em Portugal, foi determinada uma série de comportamentos que passaram a ser vistos como expressão de uma adesão oculta às doutrinas judaicas ${ }^{67}$. Neste sentido, alguns hábitos alimentares (abster-se de comer sangue, gordura animal, entre outros), práticas religiosas (as orações, a participação em cerimónias litúrgicas), ritos da tradição judaica (particularmente as celebrações do nascimento e a adolescência - sem recurso à circuncisão), o jejum em determinadas festas do ano, o preceito do sabbat ou do cumprimento de rituais que se seguiam após à morte estiveram, certamente, sob observação ${ }^{68}$.

É de crer que, também no arquipélago, a comunidade tivesse estado atenta aos comportamentos dos indivíduos: desde as manifestações de culto, à presença nas celebrações litúrgicas e sacramentais, a postura face a determinados actos, tudo isso pode ter contribuído para o desencadear de alguns processos. Como se pode constatar pelo relato das testemunhas, o comportamento dos distintos réus esteve sempre sob vigilância. O exemplo que se segue não é certamente excepcional, mas elucidativo desse aspecto.

O caso da família Dias, suspeita de judaísmo, é esclarecedor a esse respeito, como se pode comprovar pelo depoimento das testemunhas do processo: Jerónimo Gonçalves em seu testemunho declarou que as escravas de Mécia Dias se queixavam que ela as mandava trabalhar aos domingos e que folgavam aos sábados ${ }^{69}$; Inácio Fernandes disse que, na casa de Mécia Dias estava um crucifixo metido num corno ${ }^{70}$; Lourenço Francisco acrescenta ainda, que ouviu dizer que na casa de Manuel Dias havia uma cabeça de vaca e que a adoravam ${ }^{71}$.

Note-se que o hábito quotidiano era observado atentamente e era alvo de múltiplos comentários e tema de conversas frequentes. Assim, os compor-

${ }^{67}$ Ver PALOMO, Federico - A Contra-Reforma em Portugal 1540-1700. Lisboa: Livros Horizonte, 2006, p. 113-114.

${ }^{68}$ Ver idem, p. 114.

${ }^{69}$ Ver DGA/TT, Inquisição de Lisboa, Processo no 13107 , fl. 3.

${ }^{70}$ Ver ibidem.

${ }^{71}$ Ver ibidem. 
tamentos que se considerassem estranhos e levantassem algum tipo de suspeita eram denunciados, principalmente se os indivíduos fossem de famílias de origem judaica. Neste contexto, como afirmou José Pedro Paiva, a Inquisição foi um importante instrumento de vigilância de condutas e crenças religiosas que contribuiu para o disciplinamento da população cristã-velha; impulsionou acções que estimularam a perpetuação de políticas de segregação social, responsáveis por uma rígida padronização de determinados comportamentos sociais destinados a preservar um bem imaterial indispensável para sobreviver na sociedade de Antigo Regime em Portugal, a limpeza de sangue ${ }^{72}$.

Uma das estratégias utilizadas para contornar essa situação foi a fuga. Como seria de esperar, aumentaram os casos de fuga quer da Ilha de Santiago para a costa da Guiné quer para outros locais. Assim escapavam às autoridades. Tal como no Reino, também nas ilhas a fuga era um dos meios mais usados para "pôr a fazenda em seguro" e evitar os castigos, a calúnia e os prejuízos que uma intervenção da Inquisição acarretava ${ }^{73}$. Os documentos revelam que a fuga para a Guiné era usual e preocupava as autoridades locais, porque a sociedade sofria consequências directas e indirectas com essas saídas ${ }^{74}$. O quadro que não pode deixar de ser considerado é o impacto sobre a economia: primeiro, porque o arquipélago perdeu muitos empreendedores e agentes com grande volume de capitais. Segundo, porque muitos indivíduos que se fixavam na costa africana desenvolviam uma actividade comercial à margem das ilhas, escapando ao pagamento de taxas nas transacções das mercadorias, resultando em grandes prejuízos financeiros. Acrescem ainda outros efeitos económicos que contribuíram

${ }^{72}$ Ver PAIVA, José Pedro - Texto de introdução à primeira sessão de Seminário História Religiosa Moderna, realizada a 17 de Março de 2009, (http://www.ucp.pt/site/resources/ documents/CEHR/SeminarioModerna/2009/Moderna2008_S1_Apresentação.pdf, consultado em 2010.03.15).

${ }^{73}$ A questão sobre a fuga para escapar às malhas da Inquisição já foi devidamente explorada por José Pedro Paiva, em relação à uma localidade da Serra da Estrela, Melo, ver PAIVA, José Pedro Paiva - As entradas..., cit., p. 201.

${ }^{74}$ Ver DGA/TT, Inquisição de Évora, Visitas, Livro 588, fl. 8v; CARREIRA, António - Cabo Verde: formação..., cit., p. 77-78; HAVIK, Philip - La sorcellerie, l'acculturation et le genre: la persécution religieuse de l'Inquisition portugaise contre les femmes africaines converties en Haut Guinée (XVIIe siècle), in BETHENCOURT, Francisco e HAVIK, Philip (org.) - Inquisição em África. Revista Lusófona de Ciência das Religiões. 5/6 (2004), p. 99. 
para a descapitalização do território: como o confisco de bens, o fisco real (geralmente parte do património deixado, tanto pelos presos como pelos que fugiam, eram vendidos pelo juiz do fisco, o que implicava sempre sangria de capitais locais para os cofres do fisco reali5) e a transferência de capital para fora do arquipélago. Houve também interferências no processo de arrendamento das ilhas, provavelmente com alguns prejuízos financeiros para o monarca. Porventura, na base da crise económico-financeira vivida em Cabo Verde, a partir do século XVII, estava a fuga dos cristãos-novos para a costa da Guiné.

E deve sublinhar-se que essa crise económica se alastrou, de igual modo, ao domínio religioso, afectando a actuação dos bispos, obrigando-os a adaptar-se à nova situação.

A par do prejuízo económico resultante da concorrência com as grandes potências europeias (Inglaterra, Holanda e França), no trato e resgates na costa da Guiné, que porventura tenha dificultado as relações diplomáticas, houve também prejuízos para a Igreja sobretudo com as probabilidades de uma possível propagação do protestantismo. Por outro lado, temia-se que muitos dos que fugiam para a Guiné regressavam à "lei mosaica" ou aos cultos locais.

Além das implicações económicas, a sociedade cabo-verdiana sofreu também implicações noutras áreas. No domínio da política, a partir da década de 40 do século XVI, muitos cristãos-novos que ocupavam altos cargos na administração foram perseguidos e acusados, por se considerar que muitos deles foram coniventes com os desertores, por lhes possibilitarem a fuga ${ }^{76}$.

No que diz respeito às implicações culturais, foram tomadas algumas medidas preventivas referentes ao ultramar, inclusive Cabo Verde. Em instruções expressas na carta régia ao vice-rei de Portugal de 22 de Fevereiro de 1605, determinou-se que, os bispos ultramarinos vigiassem o embarque de livros da "doutrina errada" 77 . Como bem sublinhou José Pedro Paiva, a censura literária dificultou a circulação de ideias. Até os bispos que tinham o poder de magistério para ensinar a verdade da religião, para

\footnotetext{
${ }^{75}$ Ver PAIVA, José Pedro Paiva - As entradas..., cit., p. 205.

${ }^{76}$ Ver DGA/TT, Inquisição de Évora, Visitas, Livro 588, fl. 8v.

${ }^{77}$ Cf. BRÁSIO, Padre António - Monumenta ..., vol. IV, cit., p. 60-61 (Carta régia ao vice-rei de Portugal de 22 de Fevereiro de 1605).
} 
imprimir seus pensamentos tinham que os submeter a Inquisição. Contudo, isso não trouxe nenhum mal estar relacional entre os bispos e à Inquisição ${ }^{78}$.

O Santo Ofício, além de ter funcionado como mecanismo de promoção social, na medida em que atestava a "pureza do sangue", funcionou também no sentido inverso como mecanismo de distinção social - "obstruíam o acesso da população cristã-nova às carreiras nobilitantes" ". Importa lembrar que os cristãos-novos que durante os séculos XV e XVI, assumiram cargos importantes em Cabo Verde, a partir da segunda década do século XVII, foram confrontados formalmente com um alvará do rei para o bispo de Cabo Verde que lhes impedia de aceder aos cargos eclesiásticos ${ }^{80}$.

Convém ainda salientar um outro aspecto - a reintegração dos indivíduos na sociedade após à prisão. Depois de terem enfrentado um longo período de interrogatórios desde a prisão até à realização do auto-da-fé, deparam com um novo dilema - a reinserção social. Posteriormente à prisão, as oportunidades de integração eram ainda mais remotas, advindas da falta de meios causada pelos confiscos, pela desestruturação familiar e pela repugnância dos conterrâneos ${ }^{81}$. Como por exemplo, sucedeu com Manuel Dias, que depois de solto solicitou licença aos inquisidores para regressar a Cabo Verde e reaver a sua fazenda " [...] por nom se acabar de perder de todo [...]", queixando-se das dificuldades por que passava a família. O pedido foi aceite, mas os outros membros da família deveriam ficar em Lisboa ${ }^{82}$.

O impacto da acção inquisitorial repercutiu-se, por um lado, sobre as pessoas individualmente ou sobre uma determinada família e, por outro, sobre a própria sociedade cabo-verdiana que se ressentiu dos seus efeitos em vários domínios, económico, religioso, político, cultural e social.

${ }^{78}$ Ver José Pedro Paiva - Bispos, Imprensa..., cit., p. 732.

${ }^{79}$ Cf. TORRES, José Veiga - Da repressão religiosa para a promoção social. A Inquisição como instância legitimadora da promoção social da burguesia mercantil. Revista Crítica de Ciências Sociais. 40 (1994), p. 118-119.

${ }^{80}$ Ver BRÁSIO, Padre António - Monumenta Missionaria Africana. África Ocidental (1623-1650). Lisboa: Academia Portuguesa da História, 1979, vol. V, $2^{\text {a }}$ série, p. 148-149 (Alvará ao bispo de Cabo Verde de 4 de Dezembro de 1625).

${ }^{81}$ Ver PAIVA, José Pedro Paiva - As entradas..., cit., p. 203.

${ }^{82}$ Cf. DGA/TT, Inquisição de Lisboa, Processo n ${ }^{\circ}$ 13107, fl. 14. 


\section{Conclusão}

Após esta análise alcançaram-se algumas conclusões: Uma delas foi a de que os bispos, de uma forma geral, tiveram influência imediata e duradoura na acção inquisitorial no arquipélago, apoiando-a de diversas formas, e fazendo com que a sua actividade chegasse aos lugares mais remotos. O auxílio dos prelados foi decisivo no enraizamento do Santo Ofício em Cabo Verde. Os bispos assumiram a tarefa de preparar os diferentes mecanismos de actuação na sociedade. Eram eles os realizadores das visitas pastorais que, por sua vez, constituíram um meio bastante eficaz de fornecimento de casos à Inquisição. Isto porque os projectos de visitação inquisitorial que se procuraram implementar nos finais do século XVI e segunda década do século XVII não tiveram o sucesso desejado. Daí a importância da cooperação das diversas autoridades pré-existentes, mormente os bispos.

Um outro aspecto a ser ressaltado é o facto de a acção inquisitorial ter recaído sobre os cristãos-novos, sendo este um dos principais motivos da implantação do Tribunal no arquipélago, apesar de se terem também vigiado outras práticas heréticas.

Verificou-se ainda que, desde a chegada da Inquisição a Cabo Verde até à primeira metade do século XVII, período aqui analisado, houve grande entendimento entre o poder inquisitorial e o poder episcopal. Mesmo nos casos em que os bispos foram acusados de negligência no seu desempenho, como por exemplo, sucedeu com D. Bartolomeu Leitão e D. Frei Pedro Brandão, a boa relação sobrepôs-se.

Em conclusão, mesmo sem ter sido criado um Tribunal de Inquisição em Cabo Verde, esta instância não deixou de actuar, tendo deixado marcas profundas na sociedade cabo-verdiana, principalmente na comunidade cristã-nova ali residente, para o que foi decisivo o apoio que recebeu do episcopado. 